\title{
Tendiendo puentes para la convivencia
}

RAFAEL MARCOS ARANDA

Relator del Foro Iberoamericano sobre Seguridad Ciudadana, Violencia Social y Politicas Públicas. Director de programas de CICODE.

\begin{abstract}
RESUMEN
El Foro Iberoamericano sobre Seguridad Ciudadana, Violencia Social y Políticas Públicas, que se celebró en Madrid y Alcalá de Henares, entre los días 19 y 23 de junio del presente año, concluyó con la presentación de un documento de compromiso titulado "Tendiendo puentes para la convivencia". Dicho documento puede calificarse de mínimos, aunque en él se establecen una serie de consensos básicos, los cuales nos invitan a reflexionar sobre una realidad terriblemente compleja, la que afecta a la inseguridad ciudadana y a los jóvenes que se integran en pandillas y maras y cuyas causas e impactos, en términos europeos, se han investigado de forma muy superficial. Asimismo, parece importante tener en cuenta que cualquier movimiento juvenil no sólo cuenta con una serie de condicionantes multicausales (sociales, económicos, culturales, políticos, etc.), sino que además representa el fuerte deseo de expresión generacional frente a la sociedad.
\end{abstract}

Palabras clave: mara, pandilla, inseguridad, convivencia, seguridad.

El título de este artículo se corresponde con el documento final, que fue aprobado en el Foro Iberoamericano sobre Seguridad Ciudadana, Violencia Social y Políticas Públicas, que se celebró entre los días 19 y 23 de junio del presente año.

En este foro, se tuvo la oportunidad de conversar sobre los problemas de violencia so- cial que afectan a los países iberoamericanos, centrándonos sobre todo en lo referente a aquella que proviene de colectivos vulnerables, como son los jóvenes que viven en un clima de violencia y pobreza.

Me gustaría interpretar de una forma teleológica y un tanto libre, lo que se plasmó en este documento, que adelanto a decir, fue un 
documento de mínimos en cuanto a consensos básicos adoptados en dicho foro.

Reproduciré a continuación el texto íntegro de dicho documento:

El grupo de expertos, procedentes de organismos intergubernamentales, gubernamentales, de la sociedad civil y del ámbito académico y universitario iberoamericano, que hemos participado en el Foro Iberoamericano sobre Seguridad, Ciudadana, Violencia Social y Políticas Públicas, celebrado los dias 19, 20, 22 y 23 de junio de 2006, en las ciudades de Madrid y Alcalá de Henares, ante la Secretaria General Iberoamericana, expresan:

\section{Antecedentes.}

La inseguridad ciudadana es un problema que amenaza la democracia, incrementa las externalidades negativas de la economía, deteriora el capital social y cultural y la estabilidad en muchos paises de Iberoamérica y de su entorno. En algunos países es ya la demanda fundamental de la ciudadanía.

En este proceso, el desafio continúa siendo el fortalecimiento de las instituciones para que se gestionen pacificamente los conflictos.

El fenómeno traspasa las fronteras de los Estados de la Comunidad Iberoamericana.

\section{Principios generales.}

En vista de lo anterior, la situación requiere que los Estados definan propuestas regionales ante problemas comunes que comprometen la seguridad ciudadana entendida como un orden democrático, que atenúe las amenazas de la violencia en la población y permita la convivencia segura y generadora de una cultura de paz.

La participación ciudadana debe ser un elemento fundamental de estas propuestas, contando con los jóvenes como principales protagonistas.

3. Propuesta de Programa Iberoamericano. En este sentido y de acuerdo con los principios generales enunciados, a tenor de lo solicitado el día diecinueve de junio de 2006, por el Secretario General Iberoamericano, proponemos el establecimiento de un programa iberoamericano que, involucrando a la cooperación internacional de las agencias donantes, contemple las siguientes acciones:

a. La creación de una Secretaría Técnica Iberoamericana insertada en el Centro de Iniciativas de Cooperación al Desarrollo de la Universidad de Alcalá, con la misión de coordinar las actividades de la red iberoamericana de instituciones y organizaciones de reconocido prestigio, vinculadas a la temática de seguridad ciudadana, violencia social y políticas públicas, que sean convocadas de acuerdo con la Secretaría General Iberoamericana.

b. El desarrollo de un Observatorio Iberoamericano de la Seguridad Ciudadana, en coordinación con los esfuerzos ya existentes, que establezca indicadores homogéneos de medición, con la finalidad de monitorear la violencia social y facilitar el diseño de las políticas públicas.

c. El establecimiento de un Foro Anual, para el intercambio de experiencias y la definición de estrategias generales de politicas. d. La publicación de un informe anual 
sobre el estado de situación de la violencia $y$ de la seguridad en Iberoamérica.

e. El desarrollo de un portal temático que permita el intercambio de experiencias y el trabajo en red de los actores vinculados a este esfuerzo.

f. El establecimiento de un sistema de formación, capacitación y actualización de los recursos humanos, relacionados con la prevención y gestión de la violencia social.

Es lo que tenemos a bien recomendar en la Universidad de Alcalá, ciudad de Alcalá de Henares, el veintitrés de junio de 2006.

Efectivamente, podemos comprobar que la inseguridad ciudadana es uno de los elementos que limita de una forma fundamental el desarrollo democrático y el desarrollo humano, entendido éste de una forma integral.

Tanto el fenómeno de las maras como el ingreso de los individuos jóvenes en las mismas es, sin duda, reflejo de una realidad enormemente compleja cuyas causas e impactos, en términos europeos, se han investigado de forma muy superficial. Asímismo, parece importante tener en cuenta que cualquier movimiento juvenil no sólo cuenta con una serie de condicionantes multicausales (sociales, económicos, culturales, políticos, etc.), sino que además representa el fuerte deseo de expresión generacional frente a la sociedad.

Los jóvenes iberoamericanos se ven afectados, en su gran mayoría, por la pobreza y la desigualdad socioeconómica, la falta de educación y formación adecuadas, un mercado laboral que no les brinda oportunidades ni perspectivas, así como por la rápida y descontrolada urbanización, en parte basada en desplazamientos forzados, con consecuente falta de calidad de vivienda y servicios básicos.

La fuerte desintegración familiar y el extenso fenómeno de madres solteras conlleva una falta de atención de menores en todos los niveles. Existe además un modelo represivo de educación, basado en el castigo y la violencia física, reproducido generacionalmente e intensificado por un machismo cada vez más brutal. El maltrato, el abuso sexual y la violencia intrafamiliar aparecen como parte fundamental de las causas que llevan a los jóvenes a incorporarse a las maras. Los jóvenes pandilleros se ofrecen a sí mismos como una alternativa de familia, de solidaridad, seguridad y protección. En un país con graves rasgos de descomposición social donde los jóvenes no encuentran referentes para construir su propia identidad, las pandillas se presentan como alternativa a partir de las expresiones de fuerza, valor y violencia. Un alto porcentaje de jóvenes pandilleros provienen de hogares desintegrados, de graves experiencias de abuso sexual, a veces de sus propios padres, y expresan un fuerte resentimiento contra su propia familia y contra su entorno en general.

Aparte de una democracia frágil y falta de líderes políticos y sociales legitimados, pervive una cultura de impunidad y una policía en descrédito. El legado violento de las guerras civiles y la extrema represión marcó las experiencias sociales de más de una generación (violencia institucionalizada sobre todo a fi- 
nales de los 70 y principios de los 80 ). Conllevó el aprendizaje de un modelo de medios violentos y represivos para alcanzar metas y objetivos frente a la represión. Asimismo, influye la desaparición forzosa de estructuras y líderes convencionales de movimientos sociales, incluidos los juveniles.

La incidencia del crimen organizado, especialmente narcotráfico, es muy alta y mantiene cierta vinculación al Gobierno y fuerzas de seguridad («poderes paralelos»).

En el caso concreto de las pandillas, se percibe además una acelerada descomposición e ineficacia de la institucionalidad judicial, con las consecuentes pérdidas de confianza y credibilidad por parte de la población, ya que las instituciones no son capaces de garantizar la seguridad ciudadana. Se ha dado un fuerte proceso de criminalización, redadas masivas y encarcelamiento contra jóvenes por delitos menores tal como la posesión de drogas para el consumo. Estos casos no se investigan y los jóvenes son devueltos a la calle tres o cuatro meses después por falta de pruebas. Esta estancia en la cárcel, en su mayoría instalaciones totalmente desbordadas, conlleva un acercamiento de jóvenes a estructuras más estables de pandillas y al crimen organizado, por lo que fomenta un proceso de introducción de jóvenes a la delincuencia organizada y violenta.

En la pandilla podemos destacar un sentimiento de "protección" en grupo (frente a familia y otros jóvenes) y de pertenencia claramente definida (tatuajes, graffiti, etc.) frente a la falta de espacio para la contestación juvenil y la libre expresión, y, en general, un muy alto grado de desconfianza hacia «lo joven". Desde finales de las guerras civiles, se ha acelerado la pérdida de valores como tolerancia, solidaridad y respeto de derechos de los demás.

Los jóvenes entran en contacto con drogas a una edad cada vez más temprana, lo que en algunos casos causa una mayor tolerancia hacia el uso de la violencia. Persiste un influyente modelo heroico del delincuente o bandido entre los jóvenes, unido a una muy alta disponibilidad de armas de fuego e informaciones concretas sobre técnicas y formas de delincuencia. La infraestructura pública para ocio, actividades culturales y deporte es insuficiente en todos los términos. Finalmente, existe entre los jóvenes la percepción de altos beneficios económicos en actividades ilícitas, sobre todo cuando están vinculadas con el narcotráfico.

En la construcción de todo este modelo de identidad destaca la importación del modelo de bandas juveniles violentos ("Bronx") y rápido aprendizaje en formas de delincuencia juvenil organizada existente en Estados Unidos. Gran número de jóvenes en Honduras, El Salvador y Guatemala emigran a EE. UU. buscando mejores oportunidades de vida, donde se encuentran con una fuerte marginalidad $y$, en ocasiones, entran en redes delincuentes. Las autoridades norteamericanas ejercen una estricta política de deportación (devolución forzosa) de jóvenes emigrantes delincuentes principalmente desde Los Ángeles, sin que se cuente con una red de reinserción en el país natal, ahora receptor (falta de coordinación). Sobre todo la pandilla18 y la mara Salvatrucha son dirigidas 
directamente por pandilleros ubicados en territorio estadounidense. Existe comunicación permanente entre los líderes foráneos y los locales por la vía telefónica y debido a la naturaleza altamente disciplinada y vertical de los grupos de jóvenes pandilleros, las orientaciones $\mathrm{u}$ órdenes recibidas de los más altos jefes son acatadas sin mayor discusión. El problema adquiere mayor gravedad cuando se constata que buen número de los grupos pandilleros en Estados Unidos tienen estrechos lazos con la mafia y con el crimen organizado de aquel país.

Los resultados sociales de las pandillas o maras se encuentran, en primer lugar, en un notable aumento de la inseguridad ciudadana por los actos que cometen sus miembros en las calles, lo que sin duda es el efecto más visible e inmediato. A su vez, esta inseguridad ciudadana conlleva riesgos para la gobernabilidad, y representatividad del Estado, posibles reacciones altamente represivas por parte de las fuerzas de seguridad, aceptación implícita de recorte de derechos por parte de una población angustiada, así como la creación de un entorno económico desfavorable y poco propicio para inversiones productivas. De estos aspectos, ni mucho menos exhaustivos, se desprende la conclusión de que afecta muy negativamente al desarrollo humano integral, especialmente en las zonas directamente afectadas. Es de resaltar que el aumento de violencia provoca, en líneas generales, una reacción agresiva e igualmente violenta, siempre y cuando no existen modelos de prevención y gestión de conflictos capaces de evitar el uso de la violencia y negociar la situación específica de los actores.
No cabe duda de que el fenómeno de las pandillas o maras beneficia de forma directa al crimen organizado que utiliza a los jóvenes como mano de obra barata para la distribución de drogas, entrega de dinero, asesinatos, ajustes de cuentas y secuestros. Según movimientos guatemaltecos de derechos humanos, existe además una vinculación de las maras con mandos policiales corruptos y "poderes paralelos", mediante la que se coordinan actos violentos para desviar la atención de la población. En este sentido, es sintomático el hecho de que en todas las áreas en las cuales operan estos grupos, los cuerpos policiales se benefician de su acción delictiva. Es decir, todos los jefes de maras sobornan a los oficiales y agentes policiales, que cobran cuotas en efectivo o «en especie» semanal o quincenalmente: móviles y dinero en efectivo. En algunas áreas, agentes policiales alquilan armas, por día, a jóvenes pandilleros para la realización de actos delincuenciales. Así, en algunas áreas, los pandilleros y otros grupos delictivos cobran urentas o impuestos de guerra" bajo amenazas de muerte a negocios, autobuses urbanos, camiones distribuidores de productos, etc.

En el plano más político, la focalización del problema de la inseguridad pública en el fenómeno de las pandillas no solamente permite desenfocar otros aspectos sociales urgentes, sino que suele encubrir otras causas más pertinentes de esta inseguridad, tal como la amplia presencia del narcotráfico, la militarización y privatización de la seguridad, la implicación de capas del poder económico y político en actividades ilícitas a gran escala, etcétera. 
Sin duda, los altos índices de inseguridad han disminuido la capacidad de movilización de la población frente a los graves problemas sociales y frente a los altos índices de corrupción observados en el ejercicio del poder público. La población ha sido colocada, a través del terror generado por la proliferación de actos delincuenciales que quedan impunes, en una especie de adormecimiento e insensibilidad ante miles de asesinatos y de incapacidad para el ejercicio de sus derechos ciudadanos.

Sin embargo y a largo plazo, una de las consecuencias más graves del fenómeno se encuentra en la pérdida de toda una generación de jóvenes marcados por la violencia extrema, que directa o indirectamente conocieron en su niñez, tanto por las represalias de regímenes militares, como en sus familias, y que la uti- lizan como herramienta cotidiana de interactuación social; no solamente en actos delictivos a otras personas, sino también, y sobre todo, contra ellos mismos, tanto entre las diferentes pandillas como dentro de éstas. En este sentido, a lo largo del 2003, solamente en Guatemala murieron de forma violenta unos 1.185 menores de 22 años. Fuertemente hipotecada con su pasado, la sociedad guatemalteca observa cómo amplios grupos de jóvenes ya no se insertan en ella, ni en el mercado laboral, ni en sus estructuras familiares o sociales, ni en su organización política.

Para concluir, y sobre todo, este aspecto de la creación de una sociedad paralela violenta, lejos de ser percibida en todas sus dimensiones, equivale a la anulación de cualquier futuro desarrollo humano.

\begin{abstract}
The Latin American Forum on Civil Security, Social Violence and Public Policies, which met in Madrid and Alcalá de Henares from June 19 to 23,2006 , concluded with the presentation of an agreement under the heading "Building bridges for coexistence». This document, however, is only a starting point, tough it establishes a basic consensus that leads to a reflection on a very complex reality that bears on civil security and on the youths that join juvenile gangs and "maras». The causes and effects of his have so far been investigated in Europe only superficially. In relation to this, it must be taken into account that underlying any youth movement there is a series of conditions (social, economic, cultural, political, among others), and the desire to express a generation's opposition to society.
\end{abstract}

Key words: mara, gang, insecurity, safety. 